\title{
Hysteretic active control of base-isolated buildings
}

\author{
Francesc Pozo(i) | Yolanda Vidal(1) | Guillem Garcia | Leonardo Acho(i) | José Rodellar(i)
}

Control, Modeling, Identification and Applications (CoDAlab), Departament de Matemàtiques, Escola d'Enginyeria de Barcelona Est, Universitat Politècnica de Catalunya, Campus Diagonal-Besòs, Eduard Maristany, 16, Barcelona 08019, Spain

\section{Correspondence}

Francesc Pozo, Control, Modeling, Identification and Applications, Departament de Matemàtiques, Escola d'Enginyeria de Barcelona Est, Universitat Politècnica de Catalunya, Campus

Diagonal-Besòs, Eduard Maristany, 16, Barcelona 08019, Spain.

Email: francesc.pozo@upc.edu

\section{Funding information}

Spanish Ministry of Economy and Competitiveness, Grant/Award Number: DPI2017-82930-C2-1-R, DPI2014-58427-C2-1-R and

DPI2015-64170-R; Catalonia Government (Generalitat de Catalunya), Grant/Award Number: 2017 SGR 388

\begin{abstract}
Summary
In this work, an active control law for base-isolated buildings is proposed. The crucial idea comes from the observation that passive base-isolation systems are hysteretic. Thus, an hysteretic active control strategy is designed in a way that the control force is smooth and limited by a prescribed bound. Furthermore, given a specific actuator with a physically limited maximum force and maximum rate of change, it is proven that the design parameters in the contributed control law can be chosen such that the control signal inherently satisfies the actuator constraints. Eight different ground-acceleration time-history records and a model of a 5-story building are used to study and compare the performance of a passive pure friction damper alone, with the addition of the proposed active control. Numerical analysis demonstrates that our control strategy effectively mitigates base displacement and shear without an increase in superstructure drift or acceleration.
\end{abstract}

\section{KEYWORDS}

active control, base-isolated building, bounded control, hysteresis, rate of change

\section{1 | INTRODUCTION}

Civil structures are affected by several kinds of dynamic excitations such as earthquakes; winds; or, in the case of bridges, traffic loading. In this regard, base isolation has been extensively considered as an adequate technology to protect flexible building structures producing a dynamic decoupling of the structure from its foundation. ${ }^{1-3}$ However, the resulting base displacement may be excessive. Consequently, the combination of active or semiactive systems installed along with passive base-isolation bearings may alleviate the negative effects of such loads. An excellent state-of-the-art review of structural control systems is given in Saaed et $\mathrm{al},{ }^{4}$ where these systems are classified into four main groups: passive; semiactive; active; and hybrid systems, based on their operational mechanisms. Two more reviews are also proposed in Casciati et $\mathrm{al}^{5}$ and Basu et $a l,{ }^{6}$ the last one being focused on recent approaches in civil structural control across Europe.

The traditional passive base-isolation approaches can suppress the seismic responses of the upper structure, but, at the same time, they can induce substantial deformation of the base-isolation device. ${ }^{7}$ An excessive base drift may cause the degradation and even the damage of the base-isolation system. Therefore, supplemental control devices can be implemented in the common base-isolation system to construct hybrid control systems and reduce the base drifts of structures.

Semiactive control of base-isolated structures has received in the last few years an enormous attention, as they consume less power than active devices but allow controllability over passive systems. ${ }^{8}$ In fact, the combination of base-isolated 
structures with complementary variable damping devices has been successful in reducing the base-isolator displacements without increasing the building superstructure response when subjected to earthquake loads. It is noteworthy the amount of work dedicated to semiactive structural vibration control of base-isolated buildings using magnetorheological dampers thanks to its self-adaptability and high-authority controllability. For example, in Oliveira et al, ${ }^{9}$ the control law combines a force tracking integral action with a clipped on-off adaptation rule that changes the magnetorheological damping in real time; in Li et al, ${ }^{10}$ the development and characterization of a magnetorheological elastomer-based adaptive seismic isolator is proposed; in Vu et al, ${ }^{11}$ a new semiactive control based on nonlinear inhomogeneous optimal control is proposed; and in $\mathrm{Gu}$ et al, ${ }^{12}$ a semiactive control of magnetorheological elastomer base-isolation system utilizing learning-based inverse models is proposed.

Hybrid techniques combining passive and active devices have been also developed. For example, in Djedoui et al, ${ }^{13}$ a hybrid control with a base isolator and an active tuned mass damper is reported, where the active control force is calculated within a feedback loop by the mean of the linear quadratic controller designed to penalize the displacement and the velocity of the floor on which the active tuned mass damper is installed; in Yamamoto and Sone,${ }^{14}$ the behavior of an active mass damper installed in a high-rise building during the 2011 earthquake off Pacific coast of Tohoku is studied. In this work, we propose a hybrid control system, where the active control force is supplied by an appropriate actuator taking care of the saturation problem and rate limits. Every physical actuator is prone to saturation because of its limited capacities in amplitude and speed. ${ }^{15}$ Actuator amplitude limitation or rate limitation constitutes an important constraint on linear and nonlinear control design. Generally, actuator saturations are protection systems whose main objective is to avoid operating an actuator with violent control actions (which can be produced by a failure or a low quality of the control law implemented) and also avoid damaging the actuator and/or the structure (or object) it manipulates. ${ }^{16-18}$ Controllers that ignore actuator limitations may cause the closed-loop system performance to degenerate or even make the closed-loop system unstable and decrease the actuators lifetime.

The main contribution of this work comes from the observation that passive base-isolation systems are hysteretic. ${ }^{19-22}$ It is well known that these systems are dissipative, and their energy dissipation comes from the hysteresis effect of these devices. ${ }^{19-22}$ But being passive, they lack the benefits of active control. The contribution of this work is precisely to take advantage of an hysteretic energy dissipator but increasing its efficiency with its active realization. The controller is designed in such a way that (a) the force that is applied to the structure is bounded by a prescribed quantity-so that the control force is not beyond the capabilities of the actuator-and (b) the rate of change of the active control force is also limited, thus providing an smooth control action.

Simulation results demonstrate the ability of the design method-which is by nature bounded and with a smoothed rate of change- to attenuate the effects of seismic excitation.

The remainder of this paper is structured as follows. Section 2.2 presents the hysteretic control law, along with the system description and proofs of stability, and parameter tuning; in Section 3, the numerical results are discussed; and conclusions are drawn in Section 4.

\section{2 | CONTROL DESIGN}

\section{1 | System description}

Consider a hysteretic base-isolated building structure as shown in Figure 1. The equation of motion of a seismically excited structure with multiple degrees of freedom that is controlled by a single active force acting on the base can be described as follows ${ }^{23-25}$ :

$$
\mathbf{M} \ddot{\mathbf{x}}+\mathbf{C} \dot{\mathbf{x}}+\mathbf{K x}=-\mathbf{M} \Gamma \ddot{x}_{\mathrm{g}}-\mathbf{\Lambda} f+\mathbf{\Lambda} u,
$$

where $\ddot{x}_{\mathrm{g}}$ is the absolute ground acceleration; $\mathbf{x}=\left[x_{\mathrm{b}}, x_{1}, x_{2}, \cdots, x_{n}\right]^{T} \in \mathbb{R}^{n}$ represents the horizontal displacement of the base and each floor of the structure with respect to the ground; $n$ is the number of floors; $\dot{\mathbf{x}}$ and $\ddot{\mathbf{x}}$ are the $n+1$ dimensional vectors of the velocities and accelerations of the base and the floors of the structure; and $\mathbf{M}, \mathbf{C}$, and $\mathbf{K}$ are $(n+1) \times(n+1)$ mass, damping, and stiffness matrices, respectively, and have the following form ${ }^{24,25}$ :

$$
\mathbf{M}=\left[\begin{array}{cccc}
m_{\mathrm{b}} & 0 & \cdots & 0 \\
0 & m_{1} & \cdots & 0 \\
\vdots & \vdots & \ddots & \vdots \\
0 & 0 & \cdots & m_{n}
\end{array}\right],
$$




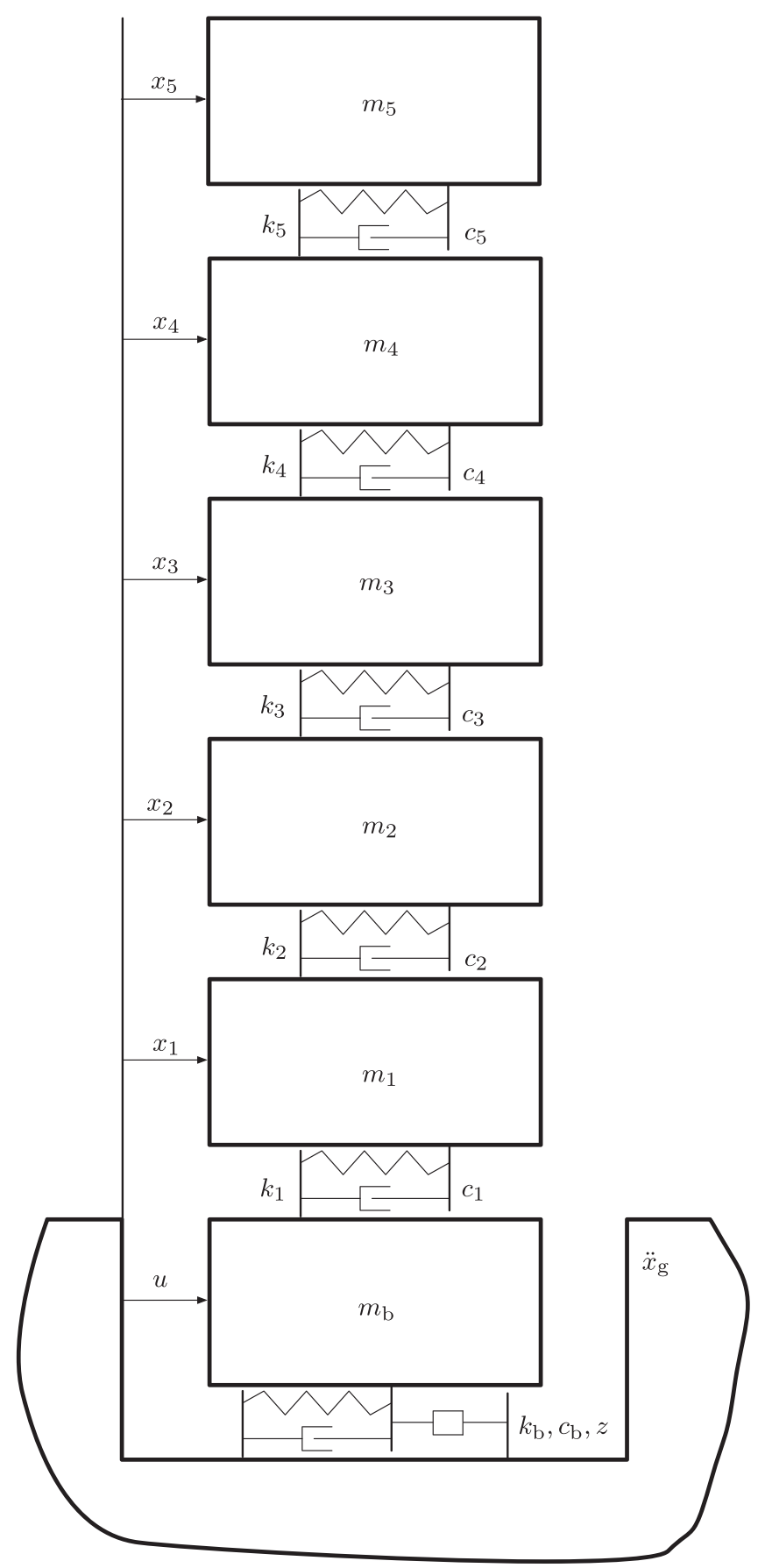

FIGURE 1 Base-isolated structure with an active control

$$
\begin{gathered}
\mathbf{C}=\left[\begin{array}{ccccc}
c_{\mathrm{b}}+c_{1} & -c_{1} & \cdots & 0 & 0 \\
-c_{1} & c_{1}+c_{2} & \cdots & 0 & 0 \\
\vdots & \vdots & \ddots & \vdots & \vdots \\
0 & 0 & \cdots & c_{n-1}+c_{n} & -c_{n} \\
0 & 0 & \cdots & -c_{n} & c_{n}
\end{array}\right], \\
\mathbf{K}=\left[\begin{array}{ccccc}
k_{\mathrm{b}}+k_{1} & -k_{1} & \cdots & 0 & 0 \\
-k_{1} & k_{1}+k_{2} & \cdots & 0 & 0 \\
\vdots & \vdots & \ddots & \vdots & \vdots \\
0 & 0 & \cdots & k_{n-1}+k_{n} & -k_{n} \\
0 & 0 & \cdots & -k_{n} & k_{n}
\end{array}\right] .
\end{gathered}
$$


The mass, damping, and stiffness of the $i$ th story are denoted by $m_{i}, c_{i}$, and $k_{i}, i=1, \ldots, n$, respectively. The base isolation is described as a single degree of freedom with horizontal displacement $x_{\mathrm{b}}$. It is assumed to exhibit a linear behavior characterized by mass, damping, and stiffness $m_{\mathrm{b}}, c_{\mathrm{b}}$, and $k_{\mathrm{b}}$, respectively, plus a nonlinear behavior represented by a hysteretic restoring force $f$, which can be represented by the Bouc-Wen model $^{26}$ in the following form:

$$
\begin{gathered}
f=\alpha z, \\
\dot{z}=-\gamma\left|\dot{x}_{\mathrm{b}}\right| z|z|^{\nu-1}-\beta \dot{x}_{\mathrm{b}}|z|^{v}+A \dot{x}_{\mathrm{b}},
\end{gathered}
$$

where $z$ is the evolutionary variable that provides information on the history dependence of the response and the parameters $\gamma, \beta, v$, and $A$ govern the linearity and smoothness of the transition from elastic to plastic response. Finally, $u$ is the control force supplied by an appropriate actuator, $\boldsymbol{\Gamma}$ is the influence coefficient matrix of size $(n+1) \times 1$, and $\boldsymbol{\Lambda}$ is the vector of size $n+1$ that specifies the placement of the base isolator and the active control force. $\boldsymbol{\Lambda}$ and $\boldsymbol{\Gamma}$ are defined as follows:

$$
\boldsymbol{\Lambda}=\left[\begin{array}{llll}
1 & 0 & \cdots & 0
\end{array}\right]^{T} \in \mathbb{R}^{n+1}, \quad \boldsymbol{\Gamma}=\left[\begin{array}{llll}
1 & 1 & \cdots & 1
\end{array}\right]^{T} \in \mathbb{R}^{n+1} .
$$

\section{2 | Hysteretic control}

\subsection{1 | Control objective and design}

We seek for an active control strategy showing the following features:

(i) to be a bounded active control in the sense that the control force that is applied to the structure is limited by a prescribed magnitude;

(ii) to be a smooth controller in the sense that the rate of change of the control force is restricted;

(iii) to be an active control using only local velocity information between the points where the device supplying the active force is connected;

(iv) to guarantee the boundedness of all the trajectories of the closed-loop system when the ground motion is striking the building; and

(v) to be an admissible controller in the sense that when the ground motion is not present, the closed-loop system is asymptotically stable.

To this end, we propose an active control strategy with the following structure:

$$
u=-\rho \cdot g\left(\dot{x}_{\mathrm{b}}\right),
$$

where the coefficient $\rho$ is a positive real number and $\dot{x}_{\mathrm{b}}$ the relative velocity of the base of the structure with respect to the ground. The use of just local velocity as input should not be considered as a severe restriction but an initial idea for a simple control law. On one hand, when $g\left(\dot{x}_{\mathrm{b}}\right)=\dot{x}_{\mathrm{b}}$, the controller is equivalent to the classical proportional velocity control equivalent to a linear damper. On the other hand, when $g\left(\dot{x}_{\mathrm{b}}\right)$ is the signum function of the velocity, that is, $g\left(\dot{x}_{\mathrm{b}}\right)=\operatorname{sgn}\left(\dot{x}_{\mathrm{b}}\right)$, the controller is equivalent to a pure friction damper. This strategy has already been reported in the literature. For instance, the control strategy in Equation 8 when $g\left(\dot{x}_{\mathrm{b}}\right)=\operatorname{sgn}\left(\dot{x}_{\mathrm{b}}\right)$ is satisfactorily applied to a benchmark base-isolated building both as an active control ${ }^{3,27}$ or as a semiactive control strategy ${ }^{28} \mathrm{~A}$ different function is considered in Pozo et al ${ }^{29}$ and Pujol et $\mathrm{al},{ }^{30}$ where $g\left(\dot{x}_{\mathrm{b}}\right)$ is defined as the product of two hyperbolic functions in the following form:

$$
g\left(\dot{x}_{\mathrm{b}}\right)=\operatorname{sech}\left(\frac{\dot{x}_{\mathrm{b}}}{\omega}\right) \cdot \tanh \left(\frac{\dot{x}_{\mathrm{b}}}{\omega}\right),
$$

where $\omega$ is a positive design parameter. In the first case, ${ }^{29}$ the active control is applied to the same benchmark structure as in Pozo et al, ${ }^{3}$ but a semiactive control implementation is also introduced. In the second case, ${ }^{30}$ the active control is applied to a benchmark highway bridge proposed by the American Society of Civil Engineers Committee on structural control. ${ }^{31-33}$ An interesting characteristic of the reported functions $g\left(\dot{x}_{\mathrm{b}}\right)=\dot{x}_{\mathrm{b}}, \quad g\left(\dot{x}_{\mathrm{b}}\right)=\operatorname{sgn}\left(\dot{x}_{\mathrm{b}}\right)$, and the function in Equation 9 is that all of them are passive in the sense that

$$
g\left(\dot{x}_{\mathrm{b}}\right) \cdot \dot{x}_{\mathrm{b}} \geq 0, \quad g(0)=0 .
$$

In this work, a different function $g$ is proposed that is based on an evolutionary variable $\eta$ as follows:

$$
g\left(\dot{x}_{\mathrm{b}}\right)=\eta,
$$




$$
\dot{\eta}=\varphi\left\{-\eta+b \operatorname{sgn}\left[c \dot{x}_{\mathrm{b}}+a \operatorname{sgn}(\eta)\right]\right\},
$$

where $\varphi$ is a positive real number and $a, b$, and $c$-also positive-are the hysteresis loop parameters shown in Figure 2 . It is worth noting that this is a bounded-input bounded-output stable system based on the hysteretic system previously proposed in Tutivén et al. ${ }^{34}$ In the current approach, the system proposed in Tutivén et $\mathrm{al}^{34}$ is modified by adding $c$, a third hysteresis loop parameter that multiplies the velocity. The transition speed between $b$ and $-b$ or viceversa is controlled by the positive parameter $\varphi$, whereas $b$ is an upper bound on the magnitude of $\eta(t)$, that is, $|\eta(t)| \leq b, t \geq 0$.

For the sake of clarity, Figure 3 represents the hysteretic loop obtained by the input $\dot{x}_{\mathrm{b}}=10 \sin (t)$ with parameters $a=b=c=1$ and $\varphi=10$.

The following assumption is specified for the system in Equations 1-7.

Assumption 1. The ground acceleration $\ddot{x}_{\mathrm{g}}$ in Equation 1 is unknown but bounded. That is, there exists a known constant $G$ such that $\left|\ddot{x}_{\mathrm{g}}(t)\right| \leq G, \quad t \geq 0$.

The boundedness of the earthquake motion in Assumption 1 is quite standard in structural control applications..$^{35,36}$ Additionally, Ikhouane et $\mathrm{al}^{37}$, theorem 1 guarantee the existence of an upper bound $Z$ on the evolutionary variable $z(t)$ in Equation 6, that is, $|z(t)| \leq Z, t \geq 0$. This upper bound, $Z$, is computable and independent of the boundedness of the base displacement $x_{\mathrm{b}}(t)$ or velocity $\dot{x}_{\mathrm{b}}(t)$.

The next theorem states the main contribution of this work with respect to the control design.

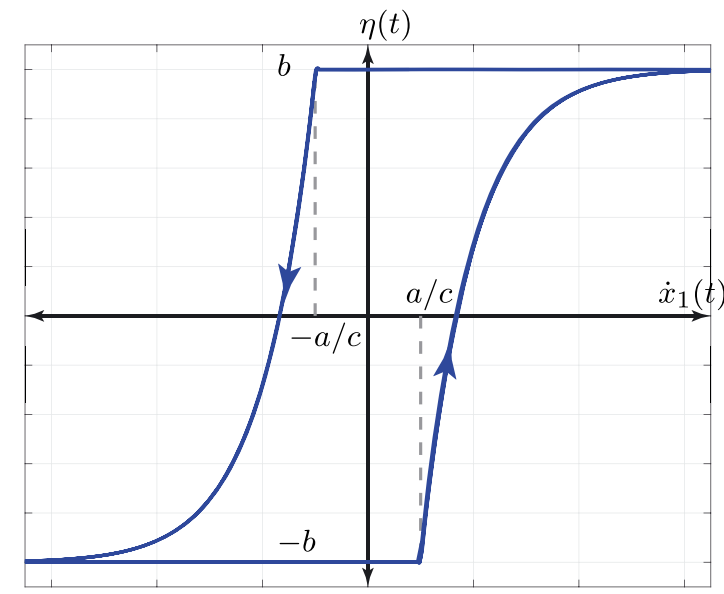

FIGURE 2 Hysteretic behavior of the system described in Equation 11

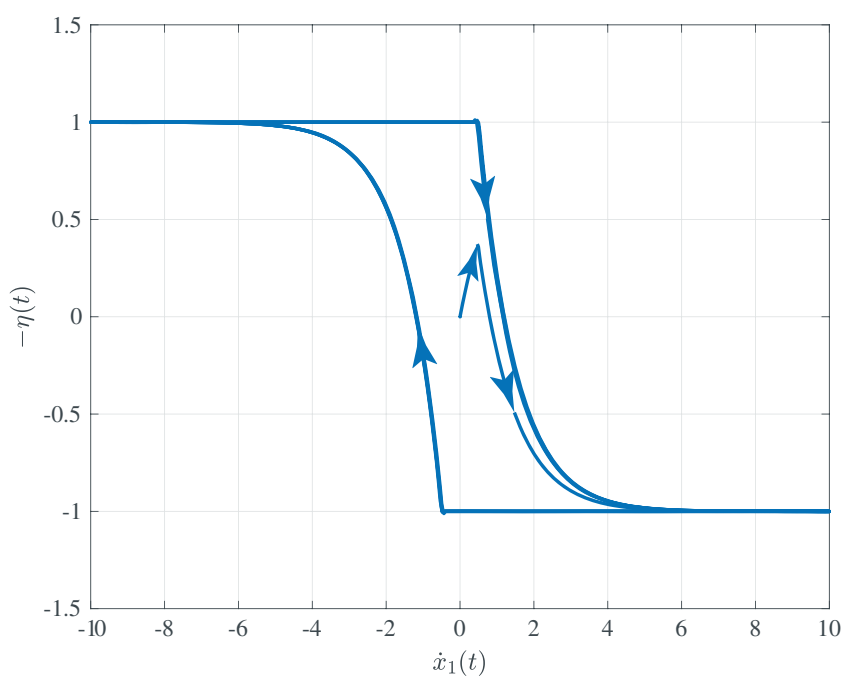

FIGURE 3 Simulation results: $-\eta(t)$ versus $x_{\mathrm{b}}(t)=10 \sin (t)$ 
Theorem 1. Consider the nonlinear system in Equations 1-6 subject to Assumption 1. Then, the control objective is achieved by the following control law:

$$
\begin{gathered}
u_{h}=-\rho_{h} \eta, \\
\dot{\eta}=\varphi\left\{-\eta+b \operatorname{sgn}\left[c \dot{x}_{\mathrm{b}}+\operatorname{asgn}(\eta)\right]\right\},
\end{gathered}
$$

where $a, b, c, \varphi$, and $\rho_{h}$ are positive design parameters. Moreover, the maximum control force is bounded by $\rho_{h} b$, that is,

$$
\left|u_{h}\right| \leq \rho_{h} b .
$$

Proof. The boundedness of $u_{h}$ comes directly from the boundedness of the evolutionary variable $\eta$ in Equations 10-(11). The proof of the stability, as in Pozo et al, ${ }^{29}$ is based on the boundedness of the ground acceleration, the evolutionary variable $z$ in Equation 6, and the control law $u_{h}$ in Equations 12-13. Due to the base isolation, it is generally accepted that the movement of the superstructure is very close to the one of a rigid body. ${ }^{38}$ Therefore, it is assumed that the superstructure is perfectly rigid so that the mass of the base $m_{\mathrm{b}}$ is replaced with the total mass $m$ of the structure:

$$
m=m_{\mathrm{b}}+\sum_{i=1}^{5} m_{i} .
$$

The equation of motion of the base can be rewritten in the form ${ }^{3,39}$

$$
\begin{aligned}
m \ddot{x}_{\mathrm{b}}+c_{\mathrm{b}} \dot{x}_{\mathrm{b}}+k_{\mathrm{b}} x_{\mathrm{b}} & =-f-m \ddot{x}_{g}+u \\
& =\underbrace{-\alpha z}_{-f}-m \ddot{x}_{g}+u_{h} .
\end{aligned}
$$

Applying the Laplace transform to the equation of motion of the base, we obtain

$$
x_{\mathrm{b}}(s)\left[m s^{2}+c_{\mathrm{b}} s+k_{\mathrm{b}}\right]=-\alpha z(s)-m \ddot{x}_{g}(s)+u_{h}(s),
$$

where $x_{\mathrm{b}}(s), z(s), \ddot{x}_{g}(s)$, and $u_{h}(s)$ are the Laplace transforms of the signals $x_{\mathrm{b}}(t), z(t), \ddot{x}_{g}(t)$, and $u_{h}(t)$, respectively. The direct transfer function between the control force $u_{h}$, the ground motion $\ddot{x}_{g}$, the hysteretic variable $z$, and the controlled base displacement $x_{\mathrm{b}}$ is

$$
\begin{aligned}
x_{\mathrm{b}}(s)= & \frac{1}{m s^{2}+c_{\mathrm{b}} s+k_{\mathrm{b}}} u_{h}(s)+\frac{-m}{m s^{2}+c_{\mathrm{b}} s+k_{\mathrm{b}}} \ddot{x}_{g}(s) \\
& +\frac{-\alpha}{m s^{2}+c_{\mathrm{b}} s+k_{\mathrm{b}}} z(s) \\
= & T_{1}(s) u_{h}(s)+T_{2}(s) \ddot{x}_{g}(s)+T_{3}(s) z(s) .
\end{aligned}
$$

For the sake of clarity, a block diagram of this system is represented in Figure 4. The three transfer functions $T_{1}(s), T_{2}(s)$, and $T_{3}(s)$ are stable. Therefore, the boundedness of the input signals $u_{h}(t), \ddot{x}_{g}(t)$, and $z(t)$ guarantees the boundedness of the output signal $x_{\mathrm{b}}(t)$, that is, the base displacement.

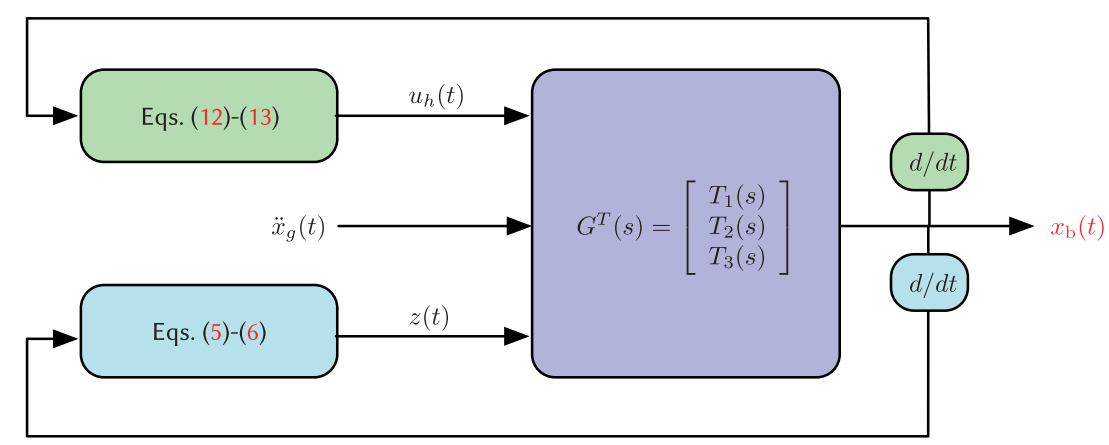

FIGURE 4 Because the transfer functions $T_{1}(s), T_{2}(s)$, and $T_{3}(s)$ are stable, the boundedness of the input signal $u_{h}, \ddot{x}_{g}$, and $z$ guarantees the boundedness of the output signal $x_{1}$ 
Proposition 1. Given a particular actuator that is able to produce a maximum force $u_{\text {max }}$ and a maximum rate of change $v_{\max }$, if $\varphi, b$, and $\rho_{h}$ in Equations 12-13 are chosen in such a way that

$$
\varphi \leq \frac{v_{\max }}{2 u_{\max }}
$$

and

$$
\rho_{h} b \leq u_{\max }
$$

then the control law in Equations 12-13 inherently satisfies the actuator physical constraints. That is,

$$
\left|u_{h}\right| \leq u_{\max }
$$

and

$$
\left|\frac{d}{d t} u_{h}\right| \leq v_{\max }
$$

Proof. On one hand, because the evolutionary variable $\eta$ in Equation 13 is bounded by $b$, then

$$
\left|u_{h}\right|=\left|-\rho_{h} \eta\right| \leq \rho_{h} b \leq u_{\max } .
$$

On the other hand, because the magnitude $\operatorname{sgn}\left[c \dot{x}_{\mathrm{b}}+a \operatorname{sgn}(\eta)\right]$ is upper bounded by 1 , it follows that

$$
\begin{aligned}
\left|\frac{d}{d t} u_{h}\right| & =\left|-\rho_{h} \frac{d}{d t} \eta\right|=\left|\rho_{h} \dot{\eta}\right| \\
& =\left|\rho_{h} \varphi\left\{-\eta+b \operatorname{sgn}\left[c \dot{x}_{\mathrm{b}}+a \operatorname{sgn}(\eta)\right]\right\}\right| \\
& =\left|-\rho_{h} \varphi \eta+\rho_{h} \varphi b \operatorname{sgn}\left[c \dot{x}_{\mathrm{b}}+a \operatorname{sgn}(\eta)\right]\right| \\
& \leq\left|\rho_{h} \varphi \eta\right|+\left|\rho_{h} \varphi b \operatorname{sgn}\left[c \dot{x}_{\mathrm{b}}+a \operatorname{sgn}(\eta)\right]\right| \\
& \leq \rho_{h} \varphi b+\rho_{h} \varphi b \\
& =2 \varphi \rho_{h} b \leq 2 \frac{v_{\max }}{2 u_{\max }} u_{\max }=v_{\max },
\end{aligned}
$$

which completes the proof.

Remark 1. The control strategy presented in Theorem 1 and defined by Equations 12-13 includes five design parameters, $a, b, c, \varphi$, and $\rho_{h}$. On one hand, according to Proposition $1, \varphi$ is related with the rate of change of the control force, so it can be selected correspondingly. On the other hand, the product $\rho_{h} b$ is related with the maximum force that has to be applied to the structure. Obviously, two sets of values $\left\{\rho_{h, 1}, b_{1}\right\}$ and $\left\{\rho_{h, 2}, b_{2}\right\}$ that have the same product

$$
\rho_{h, 1} b_{1}=\rho_{h, 2} b_{2}
$$

will keep the same bound on the control force but, probably, with a different overall performance of the control strategy.

Remark 2. The hysteretic model in Equations 10-11 is overparameterized as can be observed in Figure 2, where the role of the parameters $a$ and $c$ is related in the sense that is the ratio $\kappa=a / c$ that defines the amplitude of the hysteresis loop. More precisely, $\pm \kappa$ is the limit velocity that starts the transition for the evolutionary variable $\eta$ from $-b$ to $b$ or from $b$ to $-b$, respectively. Consequently, the overparameterization model in Equations 10-11 can be avoided by simply dividing the expression $c \dot{x}_{1}+a \operatorname{sgn}(\eta)$ in the sign function by $a$, thus resulting

$$
\begin{gathered}
g\left(\dot{x}_{1}\right)=\eta, \\
\dot{\eta}=\varphi\left\{-\eta+b \operatorname{sgn}\left[\frac{1}{\kappa} \dot{x}_{1}+\operatorname{sgn}(\eta)\right]\right\} .
\end{gathered}
$$

Therefore, the hysteresis loop parameters of the non-overparameterized model in Equations 17-18 would be the positive real numbers $\varphi, b$, and $\kappa$. 


\section{3 | SIMULATION RESULTS}

For assessing the performance of the proposed active control scheme, a base-isolated five-story building structure described by Ramallo et $\mathrm{al}^{23}$ (based on a previous work by Kelly et $\mathrm{al}^{40}$ ) is considered. This model has been intensively utilized by many researchers at the structural dynamics and control fields. ${ }^{41,42}$

For this setup, the mass, stiffness, and damping matrices are given as in Equations $2-4,{ }^{23}$ where the masses, stiffness, and damping coefficients of each floor are detailed in Table 1. The Bouc-Wen parameters in Equations 5-6 that model the base isolator are given in Table 2. These parameters are based on the optimal lead-rubber bearing designed in Ramallo et al, ${ }^{23}$ where the yield force $Q_{y}$ is defined to be the $5 \%$ of the total weight of the building.

Eight different ground-acceleration time-history records are used to excite the model of the structure. These records include

- Sylmar, $360^{\circ}$ and $90^{\circ}$ components of the 1994 Northridge earthquake recorded at the Sylmar station, fault normal (FN) and fault parallel (FP), respectively;

- Rinaldi, $228^{\circ}$ and $318^{\circ}$ components of the 1994 Northridge earthquake recorded at the Rinaldi station, FN and FP, respectively;

- Ji-Ji, north-south and east-west components of the $1999 \mathrm{Ji}$-Ji earthquake recorded at the station TCU 068 (Shikhkang), FN and FP, respectively;

- Erzinkan, north-south and east-west components of the 1992 Erzinkan earthquake, FN and FP, respectively.

These ground motions are considered to cover both moderate and severe events. More precisely, the peak ground accelerations of these earthquakes (expressed in $\mathfrak{g}$, where $\mathfrak{g}=9.80665 \mathrm{~m} / \mathrm{s}^{2}$ is the conventional standard value of the gravitational acceleration) can be found in Table 3.

TABLE 1 Structural model parameters ${ }^{23}$

\begin{tabular}{lll} 
Floor masses $[[\mathbf{k g}]]$ & Stiffness coefficients $[[\mathbf{k N} / \mathbf{m}]]$ & Damping coefficients $[[\mathbf{k N} \cdot \mathbf{s} / \mathbf{m}]]$ \\
$m_{\mathrm{b}}=6800$ & $k_{\mathrm{b}}=232$ & $c_{\mathrm{b}}=3.74$ \\
$m_{1}=5897$ & $k_{1}=33732$ & $c_{1}=67$ \\
$m_{2}=5897$ & $k_{2}=29093$ & $c_{2}=58$ \\
$m_{3}=5897$ & $k_{3}=28621$ & $c_{3}=57$ \\
$m_{4}=5897$ & $k_{4}=24954$ & $c_{4}=50$ \\
$m_{5}=5897$ & $k_{5}=19059$ & $c_{5}=38$ \\
\hline
\end{tabular}

TABLE 2 Bouc-Wen model parameters in Equations 5-6 of the base isolator ${ }^{24}$

\begin{tabular}{llll} 
Parameter & Value & Parameter & Value \\
$Q_{y}=5 \%$ building weight & $17.79 \mathrm{kN}$ & $K_{\text {yield }}=k_{\mathrm{b}}$ & $232 \mathrm{kN} / \mathrm{m}$ \\
$K_{\text {initial }}=6 \cdot K_{\text {yield }}$ & $1392 \mathrm{kN} / \mathrm{m}$ & $\alpha=\left(1-K_{\text {yield }} / K_{\text {initial }}\right) Q_{y}$ & $14.83 \mathrm{kN}$ \\
$\beta=K_{\text {initial }} /\left(2 Q_{y}\right)$ & $39.12 \mathrm{~m}^{-1}$ & $\gamma=\beta$ & $39.12 \mathrm{~m}^{-1}$ \\
$A=2 \beta=2 \gamma$ & $78.24 \mathrm{~m}^{-1}$ & $v$ & 1 \\
\hline
\end{tabular}

TABLE 3 PGA of the ground motions considered to excite the model of the structure

\begin{tabular}{llll} 
Earthquake & PGA (q) & Earthquake & PGA (q) \\
\hline Sylmar (FN) & 0.8749 & Sylmar (FP) & 0.6047 \\
Rinaldi (FN) & 0.8402 & Rinaldi (FP) & 0.4762 \\
Ji-Ji (FN) & 0.5118 & Ji-Ji (FP) & 0.3693 \\
Erzinkan (FN) & 0.5150 & Erzinkan (FP) & 0.4956 \\
\hline
\end{tabular}

Note. $\mathrm{FN}=$ fault normal; FP = fault parallel; PGA = peak ground acceleration. 
The simulation results of the hysteretic control in Equations 12-13 are compiled in Tables 5, 6 for the FN and the FP components acting in two perpendicular directions, respectively. The results of the proposed control $u_{h}$ are also compared with the pure friction damper in Pozo et $\mathrm{al}^{3}$ and Pujol et al, ${ }^{27}$ defined as $u_{s}=-\rho_{s} \operatorname{sgn}\left(\dot{x}_{\mathrm{b}}\right)$.

TABLE 4 Design parameters of the control $u_{h}$ in Equation 12

\begin{tabular}{llll} 
Parameter & Value & Parameter & Value \\
$a$ & $1 \mathrm{~m} / \mathrm{s}$ & $b$ & $0.5 \mathrm{~N}$ \\
$c$ & 1,100 & $\varphi$ & $151 / \mathrm{s}$ \\
$\rho_{h}$ & 36,000 & & \\
\hline
\end{tabular}
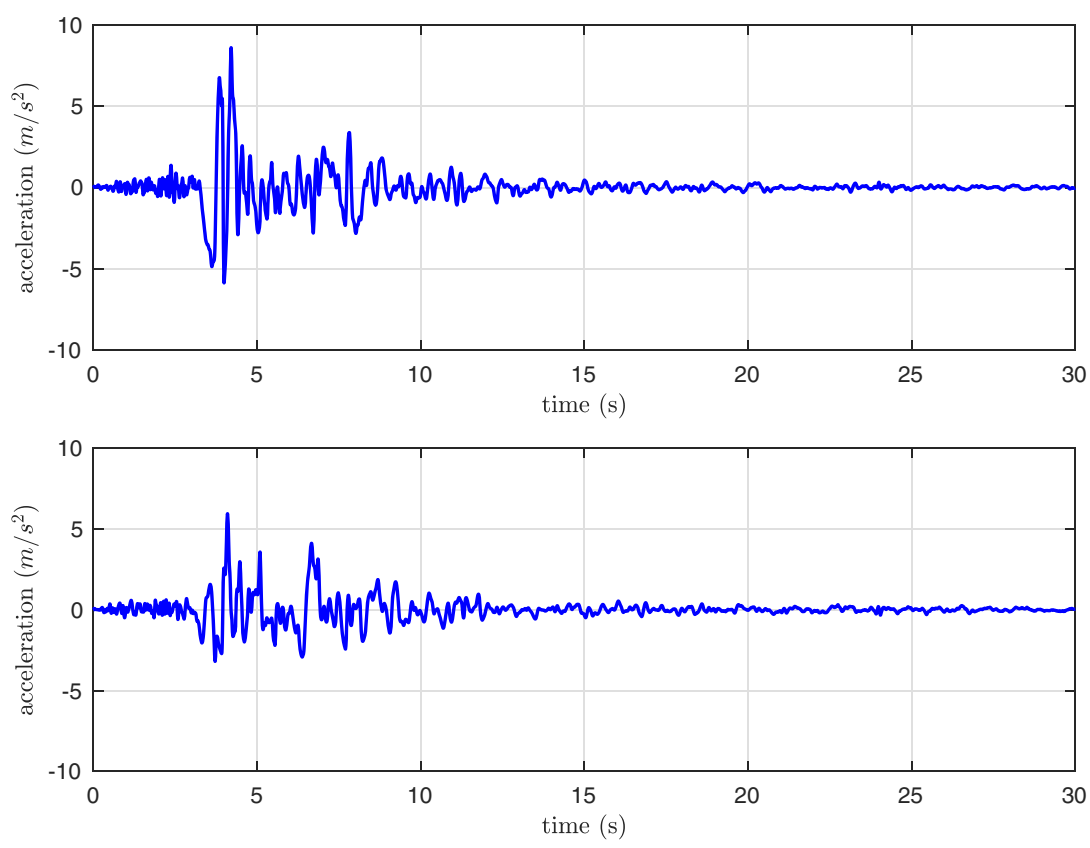

FIGURE $5360^{\circ}$ and $90^{\circ}$ components of the Sylmar record of the 1994 Northridge earthquake. Fault normal (top) and fault parallel (bottom) components

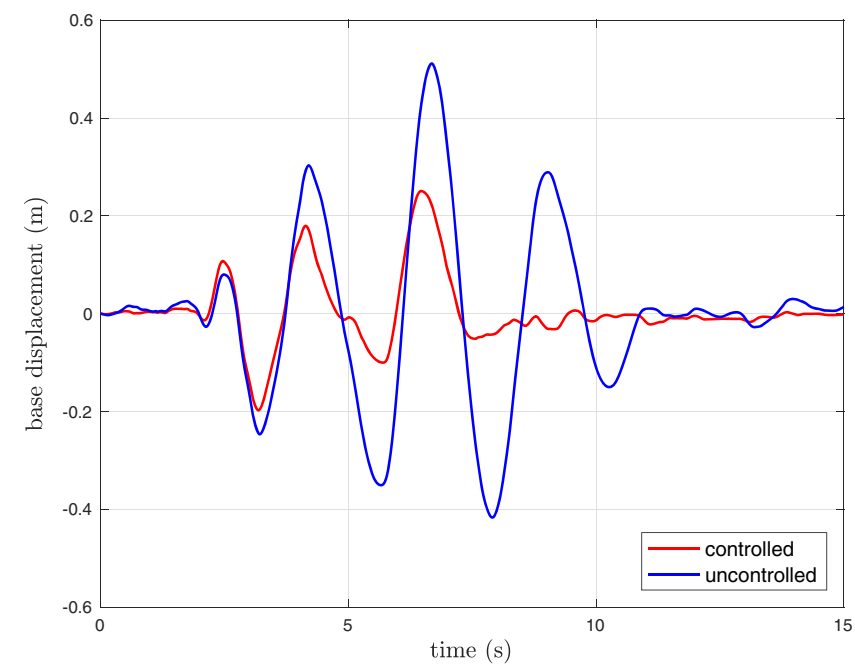

FIGURE 6 Time-history response of the isolated building under 1.0×Rinaldi-FP excitation. Displacement of the base for both the uncontrolled and the controlled situations 
The evaluation of the performance of the proposed strategy is described in terms of the evaluation criteria defined in Appendix A. The eight ground-acceleration time-history records are used at the full intensity for the computation of the evaluation criteria. Additionally, the earthquakes are also scaled to several magnitudes in the range from 0.5 to 2.0 times. An evaluation criteria smaller than 1 indicates that the response of the uncontrolled structure is bigger than that of the controlled structure. Contrarily, an evaluation criteria larger than 1 indicates the undesired case when the controlled response of the structure is bigger than that of the uncontrolled case. The cases with an evaluation criteria larger than 1 in Tables 5, 6 are highlighted with a gray-colored cell background.

\section{1 | Performance assessment in terms of the evaluation criteria}

In this section, we present the performance assessment—in terms of the evaluation criteria in Appendix A—of the control strategy in Equations 12-13 using the control parameters given in Table 4. These parameters are not obtained through optimization but via a trial-and-error approach. In some cases, a heuristic approach is used to select them. For instance, the product $\rho_{h} b$ is chosen so that the peak control force is $18 \mathrm{kN}$, similar to the isolation-layer yield force $Q_{y}=17.8 \mathrm{kN}$, which is $5 \%$ of the weight of the structure.

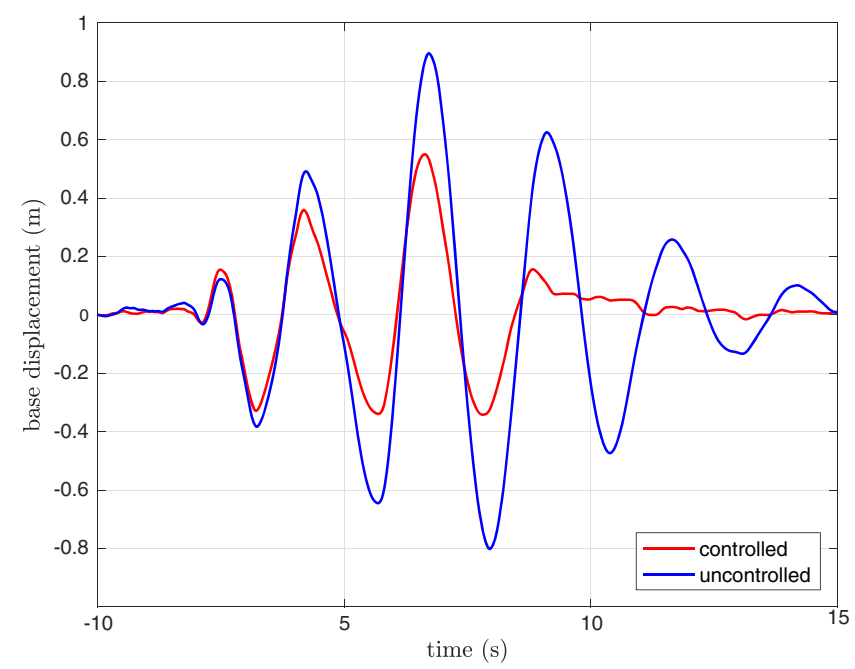

FIGURE 7 Time-history response of the isolated building under 1.5× Rinaldi-FP excitation. Displacement of the base for both the uncontrolled and the controlled situations

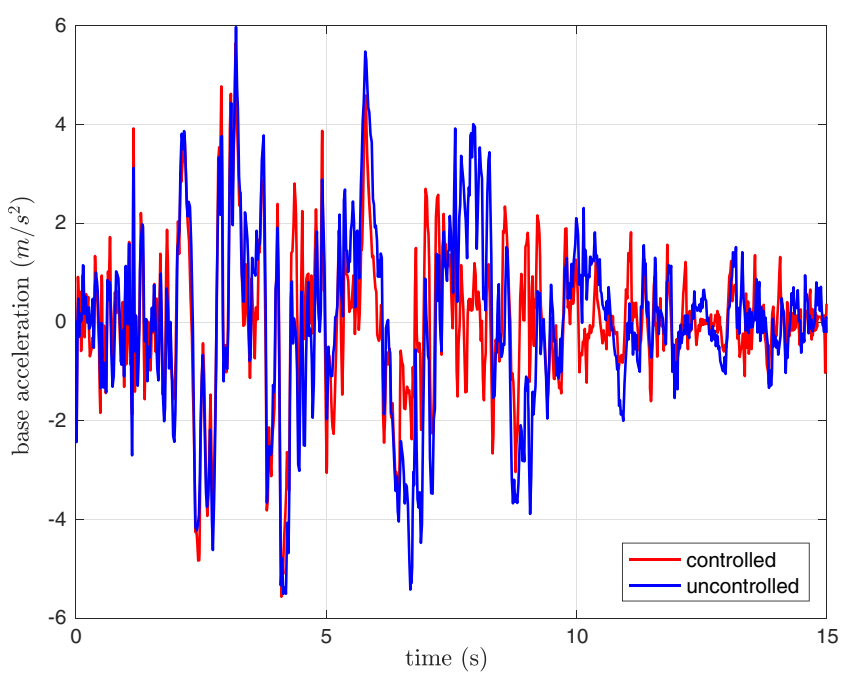

FIGURE 8 Time-history response of the isolated building under 1.0× Rinaldi-FP excitation. Absolute acceleration of the base for both the uncontrolled and the controlled situations 
The base and structural shears are reduced up to $26 \%$ in a majority of earthquakes (except $\{1.0,1.5,2.0\} \times$ Erzinkan-FP; $0.5 \times$ Ji-ji-FN; $2.0 \times$ Ji-ji-FP; $0.5 \times$ Rinaldi-FN; $1.0 \times$ Rinaldi-FP; and $\{0.5,2.0\} \times$ Sylmar-FN). The reduction in base displacement is between $6 \%$ and $72 \%$ in all cases with no exception. Reductions in the interstory drifts between $1 \%$ and $33 \%$ are achieved when compared with the uncontrolled case in all earthquakes but $0.5 \times$ Erzinkan-FP; $1.5 \times$ Erzinkan-FN; $\{0.5,1.5,2.0\} \times$ Rinaldi-FN; $0.5 \times$ Rinaldi-FP; and $0.5 \times$ Sylmar-FP. The floor accelerations are also reduced-by up to $82 \%$-in a majority of earthquakes (except $\{1.0,2.0\} \times$ Erzinkan- $\{$ FN,FP $\} ;\{0.5,1.5,2.0\} \times$ Ji-ji-FP; $0.5 \times$ Ji-ji-FN, and $\{1.0,1.5\} \times$ Sylmar-FN).

From a general point of view, the benefit of the active control strategy is the reduction in base displacement $\left(J_{3}\right)$ and shear $\left(J_{1}, J_{2}\right)$ of up to $72 \%$ without and increase in $\operatorname{drift}\left(J_{4}\right)$ or acceleration $\left(J_{5}\right)$. The reduction in the peak base displacement $J_{3}$ if the base-isolated structure is one of the most important criteria during strong earthquakes.

Although both the peak base displacement $\left(J_{3}\right)$ and the peak absolute floor acceleration $\left(J_{5}\right)$ are significantly reduced in a majority of earthquakes, it is worth noting that their equivalent root mean square (RMS) measures $\left(J_{7}\right.$ and $J_{8}$, respectively) are remarkably reduced in all the earthquakes with a few exceptions. For instance, the reduction in RMS base displacement is between $7 \%$ and $60 \%$, and the reduction in RMS absolute floor acceleration fluctuates between $1 \%$ and $53 \%$.

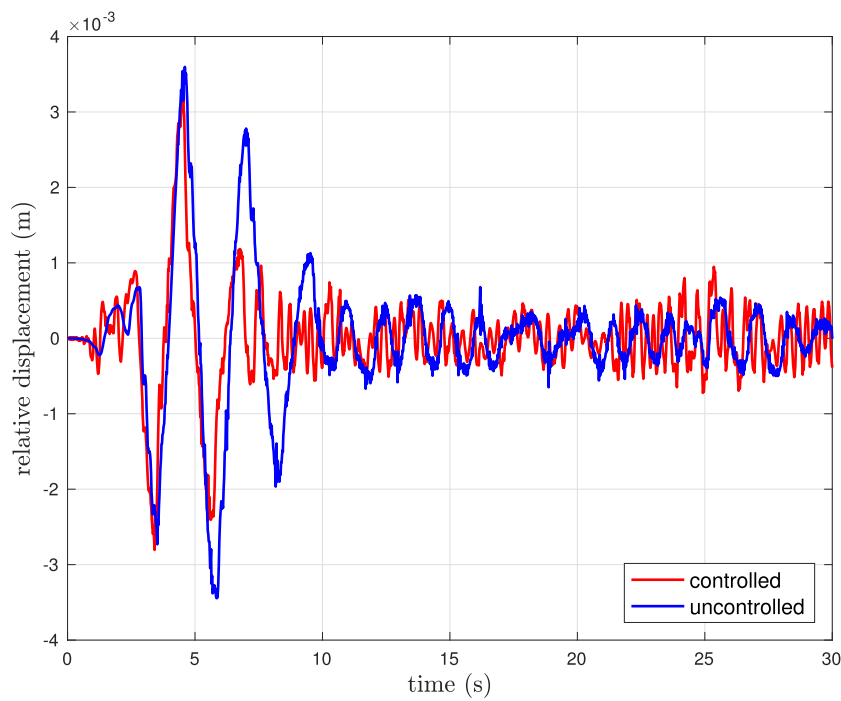

FIGURE 9 Time-history response of the isolated building under 1.0× Erzinkan excitation (fault normal). Relative displacement between the second and the first floor $\left(x_{2}-x_{1}\right)$

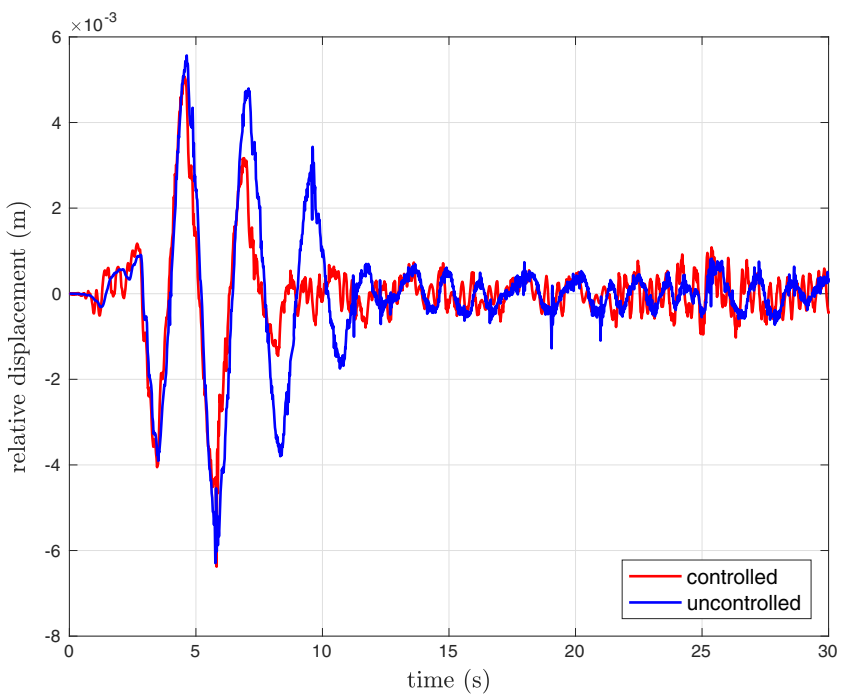

FIGURE 10 Time-history response of the isolated building under 1.5× Erzinkan excitation (fault normal). Relative displacement between the second and the first floor $\left(x_{2}-x_{1}\right)$ 
This means that even in a case where the peak base displacement in the controlled structure is reduced by only $6 \%(2.0 \times$ Rinaldi-FN)—with respect to the uncontrolled case—-the RMS base displacement is reduced by $25 \%$. Similarly, when the fault normal component of $1.5 \times$ Erzinkan earthquake is used to excite the structure, the peak absolute floor acceleration is increased by $1 \%$, whereas the equivalent RMS measure is reduced by $25 \%$. These two RMS-related evaluation criteria are somehow linked with the oscillating behavior of the structure. Therefore, low RMS-related performance indices imply a reduction in the overall structural charges that affect the building. The bound on the control force is defined as the product of the design parameters $\rho_{h}$ and $b$ in Equations 12 and 13. Consequently, the performance index $J_{6}$-which is a measure of the relative control effort of the proposed strategy-lies within a range of acceptable values (2-24\%).

\section{2 | Time-history plots}

Figures 6-10 represent the time-history plots of different magnitudes for the five-story building described in Figure 1. All these figures include the controlled response using the control strategy in Equations 12-13 (red solid lines) and the uncontrolled response (blue solid lines) using the $\{1.0,1.5\} \times$ Rinaldi-FP and $\{1.0,1.5\} \times$ Erzinkan earthquakes. Figure 5

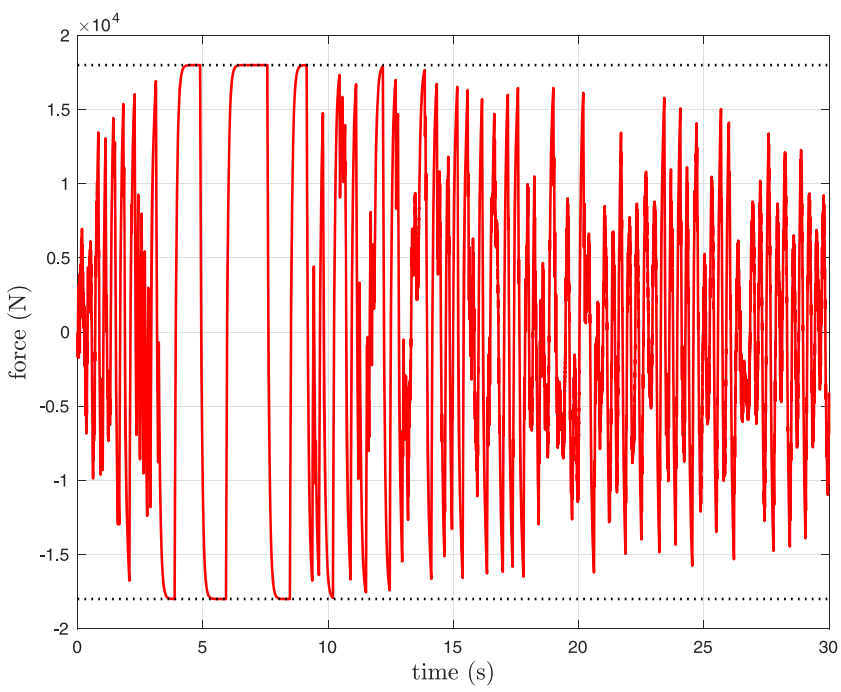

FIGURE 11 Control force under the fault normal component of the $1.0 \times$ Sylmar excitation. Note that the $u_{\max }=\rho_{h} b=18 \mathrm{kN}$ constraint is satisfied

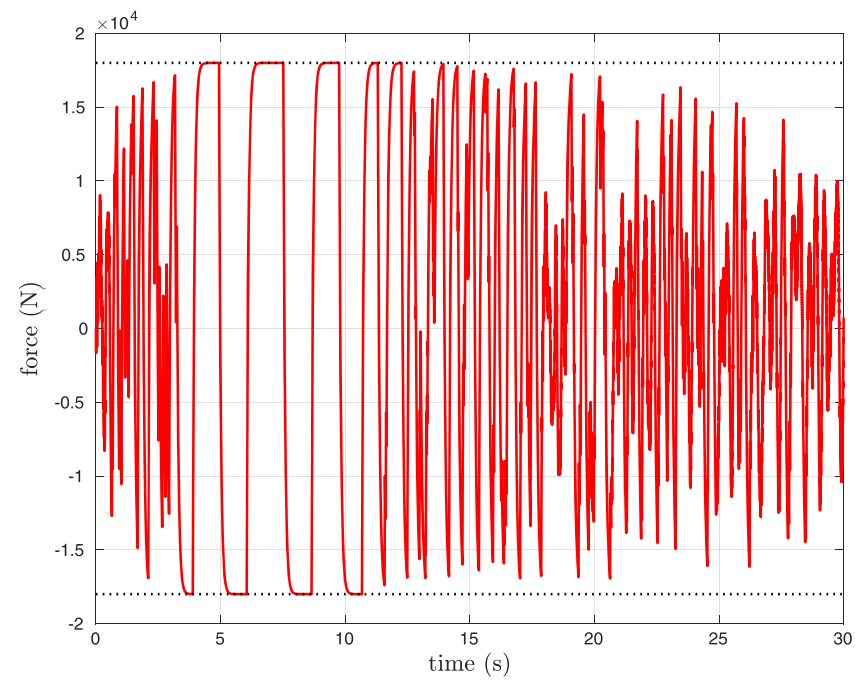

FIGURE 12 Control force under the fault normal component of the $1.5 \times$ Sylmar excitation. Note that the $u_{\max }=\rho_{h} b=18 \mathrm{kN}$ constraint is satisfied 


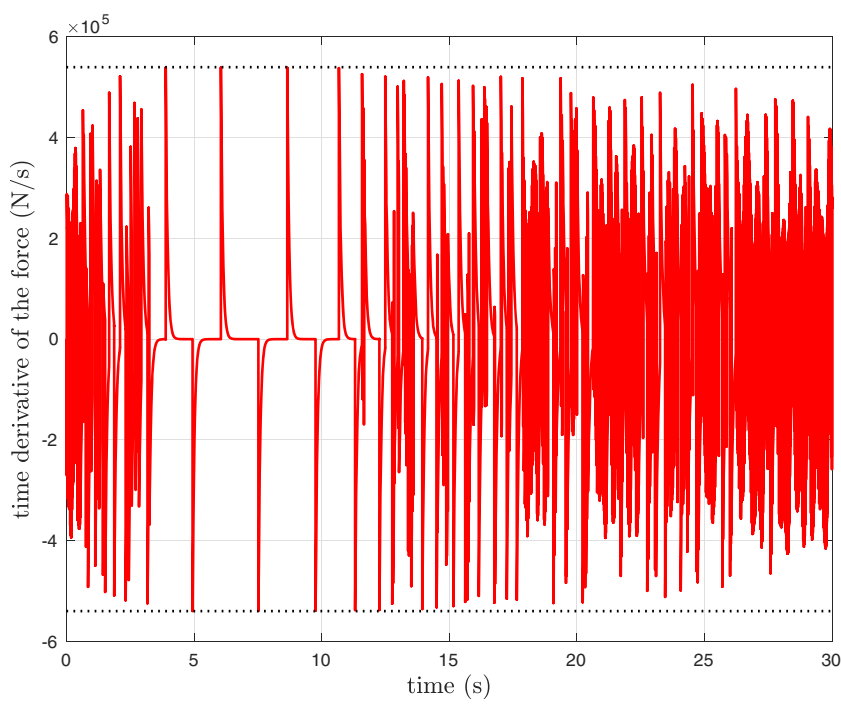

FIGURE 13 Time derivative of the control force under the fault normal component of the $1.5 \times$ Sylmar excitation. Note that the force rate limitation $v_{\max }=2 u_{\max } \varphi=540 \mathrm{kN} / \mathrm{s}$ is satisfied

TABLE 5 Results of the controllers' evaluation criteria for the so-called FN set of ground motions

\begin{tabular}{|c|c|c|c|c|c|c|c|c|c|c|}
\hline Earthquake & PGA (g) & Case & $J_{1}$ & $J_{2}$ & $J_{3}$ & $J_{4}$ & $J_{5}$ & $J_{6}$ & $J_{7}$ & $J_{8}$ \\
\hline \multirow[t]{2}{*}{$0.5 \times$ Sylmar } & \multirow[t]{2}{*}{0.4375} & $u_{s}$ & 1.04 & 1.03 & 0.43 & 1.01 & 0.99 & 0.10 & 0.38 & 0.96 \\
\hline & & $u_{h}$ & 1.05 & 1.01 & 0.51 & 0.90 & 0.76 & 0.10 & 0.42 & 0.89 \\
\hline \multirow[t]{2}{*}{$1.0 \times$ Sylmar } & \multirow[t]{2}{*}{0.8749} & $u_{s}$ & 0.98 & 0.99 & 0.72 & 0.88 & 0.96 & 0.05 & 0.46 & 0.84 \\
\hline & & $u_{h}$ & 0.96 & 0.99 & 0.75 & 0.88 & 1.17 & 0.05 & 0.48 & 0.78 \\
\hline \multirow[t]{2}{*}{$1.5 \times$ Sylmar } & \multirow[t]{2}{*}{1.3124} & $u_{s}$ & 0.94 & 0.96 & 0.72 & 0.84 & 0.99 & 0.04 & 0.54 & 0.81 \\
\hline & & $u_{h}$ & 0.93 & 0.95 & 0.75 & 0.87 & 1.03 & 0.04 & 0.57 & 0.75 \\
\hline \multirow[t]{2}{*}{$2.0 \times$ Sylmar } & \multirow[t]{2}{*}{1.7498} & $u_{s}$ & 1.01 & 1.01 & 0.72 & 0.81 & 1.00 & 0.03 & 0.61 & 0.78 \\
\hline & & $u_{h}$ & 1.01 & 0.99 & 0.74 & 0.86 & 0.99 & 0.03 & 0.64 & 0.79 \\
\hline \multirow[t]{2}{*}{$0.5 \times$ Rinaldi } & \multirow[t]{2}{*}{0.4201} & $u_{s}$ & 1.00 & 0.98 & 0.84 & 1.07 & 0.92 & 0.09 & 0.78 & 1.10 \\
\hline & & $u_{h}$ & 1.01 & 1.01 & 0.93 & 1.20 & 0.92 & 0.09 & 0.78 & 1.04 \\
\hline \multirow[t]{2}{*}{$1.0 \times$ Rinaldi } & \multirow[t]{2}{*}{0.8402} & $u_{s}$ & 0.99 & 0.98 & 0.87 & 0.93 & 0.97 & 0.05 & 0.74 & 1.13 \\
\hline & & $u_{h}$ & 0.99 & 0.99 & 0.92 & 0.96 & 0.96 & 0.05 & 0.75 & 0.96 \\
\hline \multirow[t]{2}{*}{$1.5 \times$ Rinaldi } & \multirow[t]{2}{*}{1.2603} & $u_{s}$ & 0.99 & 0.98 & 0.88 & 1.09 & 1.01 & 0.03 & 0.73 & 1.07 \\
\hline & & $u_{h}$ & 0.99 & 0.99 & 0.93 & 1.07 & 0.96 & 0.03 & 0.76 & 0.94 \\
\hline \multirow[t]{2}{*}{$2.0 \times$ Rinaldi } & \multirow[t]{2}{*}{1.6804} & $u_{s}$ & 0.99 & 0.99 & 0.91 & 1.07 & 0.96 & 0.02 & 0.74 & 1.09 \\
\hline & & $u_{h}$ & 0.98 & 0.99 & 0.94 & 1.03 & 0.98 & 0.02 & 0.75 & 0.97 \\
\hline \multirow[t]{2}{*}{$0.5 \times \mathrm{Ji}-\mathrm{ji}$} & \multirow[t]{2}{*}{0.2559} & $u_{s}$ & 1.05 & 1.04 & 0.53 & 0.88 & 0.95 & 0.15 & 0.50 & 0.69 \\
\hline & & $u_{h}$ & 1.17 & 1.11 & 0.58 & 0.85 & 1.03 & 0.15 & 0.54 & 0.76 \\
\hline \multirow[t]{2}{*}{$1.0 \times \mathrm{Ji}-\mathrm{ji}$} & \multirow[t]{2}{*}{0.5118} & $u_{s}$ & 0.91 & 0.92 & 0.60 & 0.70 & 0.21 & 0.09 & 0.44 & 0.52 \\
\hline & & $u_{h}$ & 0.92 & 0.93 & 0.62 & 0.73 & 0.18 & 0.09 & 0.45 & 0.47 \\
\hline \multirow[t]{2}{*}{$1.5 \times \mathrm{Ji}-\mathrm{ji}$} & \multirow[t]{2}{*}{0.7677} & $u_{s}$ & 0.79 & 0.77 & 0.65 & 0.70 & 0.33 & 0.06 & 0.57 & 0.61 \\
\hline & & $u_{h}$ & 0.78 & 0.79 & 0.66 & 0.74 & 0.57 & 0.06 & 0.58 & 0.60 \\
\hline \multirow[t]{2}{*}{$2.0 \times \mathrm{Ji}-\mathrm{ji}$} & \multirow[t]{2}{*}{1.0236} & $u_{s}$ & 0.74 & 0.77 & 0.70 & 0.76 & 0.70 & 0.04 & 0.65 & 0.74 \\
\hline & & $u_{h}$ & 0.74 & 0.74 & 0.71 & 0.79 & 0.50 & 0.04 & 0.66 & 0.66 \\
\hline \multirow[t]{2}{*}{$0.5 \times$ Erzinkan } & \multirow[t]{2}{*}{0.2575} & $u_{s}$ & 0.68 & 0.68 & 0.43 & 0.77 & 0.94 & 0.24 & 0.48 & 0.91 \\
\hline & & $u_{h}$ & 0.74 & 0.78 & 0.44 & 0.78 & 0.78 & 0.24 & 0.44 & 0.85 \\
\hline \multirow[t]{2}{*}{ 1.0× Erzinkan } & 0.5150 & $u_{s}$ & 0.90 & 0.87 & 0.71 & 0.85 & 1.12 & 0.09 & 0.56 & 0.83 \\
\hline & & $u_{h}$ & 0.91 & 0.92 & 0.74 & 0.89 & 1.16 & 0.09 & 0.59 & 0.72 \\
\hline 1.5× Erzinkan & 0.7725 & $u_{s}$ & 0.86 & 0.87 & 0.79 & 0.80 & 0.72 & 0.06 & 0.65 & 0.82 \\
\hline & & $u_{h}$ & 0.89 & 0.89 & 0.82 & 1.01 & 0.98 & 0.06 & 0.68 & 0.75 \\
\hline 2.0× Erzinkan & 1.0300 & $u_{s}$ & 0.88 & 0.90 & 0.81 & 0.82 & 0.81 & 0.04 & 0.69 & 0.91 \\
\hline & & $u_{h}$ & 0.93 & 0.94 & 0.83 & 0.83 & 1.10 & 0.04 & 0.71 & 0.79 \\
\hline
\end{tabular}

Note. $\mathrm{FN}=$ fault normal; PGA $=$ peak ground acceleration. 
shows the ground acceleration for the $360^{\circ}$ and $90^{\circ}$ components of 1994 Northridge earthquake. More precisely, Figures 6 and 7 present the plots for the displacement of the base under $\{1.5,2.0\} \times$ Rinaldi-FP excitation, respectively, clearly showing the efficiency of the proposed controller. The plotted magnitude in Figure 8 is the base acceleration under 1.0X Rinaldi-FP. Finally, the relative displacement between the second and the first floor is depicted in Figures 9 and 10 under the fault normal component of $\{1.0,1.5\} \times$ Erzinkan excitation, respectively. From these figures, it can be derived that the controlled response magnitudes are effectively reduced when examined in contrast with the uncontrolled responses.

Three more figures are included in this section that show the relatively low control effort. The active control force that is applied to the base of the structure under 1.0 Sylmar (FN) is illustrated in Figure 11. Similarly, Figures 12 and 13 reproduce the control effort and its time derivative, respectively, under the fault normal component of $1.5 \times$ Sylmar ground motion. It is worth remarking from the observation of these three figures that the control force is bounded as prescribed in section 2.2.1.

\section{3 | Comparison}

The results of the control strategy presented in Equations 12-13 are compared with the control law

$$
u_{s}=-\rho_{s} \operatorname{sgn}\left(\dot{x}_{\mathrm{b}}\right)
$$

TABLE 6 Results of the controllers' evaluation criteria for the so-called FP set of ground motions

\begin{tabular}{|c|c|c|c|c|c|c|c|c|c|c|}
\hline Earthquake & PGA (g) & Case & $J_{1}$ & $J_{2}$ & $J_{3}$ & $J_{4}$ & $J_{5}$ & $J_{6}$ & $J_{7}$ & $J_{8}$ \\
\hline \multirow[t]{2}{*}{$0.5 \times$ Sylmar } & \multirow[t]{2}{*}{0.3024} & $u_{s}$ & 0.83 & 0.73 & 0.55 & 1.21 & 1.18 & 0.15 & 1.11 & 1.09 \\
\hline & & $u_{h}$ & 1.00 & 0.99 & 0.65 & 1.14 & 0.94 & 0.15 & 0.93 & 1.12 \\
\hline \multirow[t]{2}{*}{$1.0 \times$ Sylmar } & \multirow[t]{2}{*}{0.6047} & $u_{s}$ & 0.92 & 0.86 & 0.54 & 0.80 & 1.08 & 0.08 & 0.40 & 0.92 \\
\hline & & $u_{h}$ & 0.98 & 1.00 & 0.61 & 0.87 & 0.88 & 0.08 & 0.44 & 0.85 \\
\hline \multirow[t]{2}{*}{$1.5 \times$ Sylmar } & \multirow[t]{2}{*}{0.9071} & $u_{s}$ & 0.94 & 0.91 & 0.63 & 0.79 & 0.99 & 0.05 & 0.47 & 0.79 \\
\hline & & $u_{h}$ & 1.00 & 1.01 & 0.68 & 0.79 & 0.93 & 0.05 & 0.50 & 0.74 \\
\hline \multirow[t]{2}{*}{$2.0 \times$ Sylmar } & \multirow[t]{2}{*}{1.2094} & $u_{s}$ & 0.96 & 0.94 & 0.68 & 0.79 & 0.97 & 0.04 & 0.52 & 0.78 \\
\hline & & $u_{h}$ & 0.98 & 0.99 & 0.72 & 0.83 & 0.95 & 0.04 & 0.55 & 0.72 \\
\hline \multirow[t]{2}{*}{$0.5 \times$ Rinaldi } & \multirow[t]{2}{*}{0.2381} & $u_{s}$ & 0.96 & 0.95 & 0.40 & 1.14 & 1.06 & 0.18 & 0.57 & 1.30 \\
\hline & & $u_{h}$ & 0.95 & 0.97 & 0.46 & 1.02 & 0.97 & 0.18 & 0.56 & 1.11 \\
\hline \multirow[t]{2}{*}{$1.0 \times$ Rinaldi } & \multirow[t]{2}{*}{0.4762} & $u_{s}$ & 0.99 & 0.97 & 0.43 & 0.63 & 0.74 & 0.09 & 0.36 & 0.93 \\
\hline & & $u_{h}$ & 1.02 & 1.00 & 0.49 & 0.67 & 0.76 & 0.09 & 0.40 & 0.86 \\
\hline \multirow[t]{2}{*}{$1.5 \times$ Rinaldi } & \multirow[t]{2}{*}{0.7143} & $u_{s}$ & 0.93 & 0.93 & 0.57 & 0.74 & 0.82 & 0.06 & 0.47 & 0.82 \\
\hline & & $u_{h}$ & 0.94 & 0.94 & 0.61 & 0.74 & 0.68 & 0.06 & 0.50 & 0.79 \\
\hline \multirow[t]{2}{*}{$2.0 \times$ Rinaldi } & \multirow[t]{2}{*}{0.9524} & $u_{s}$ & 0.88 & 0.89 & 0.69 & 0.76 & 0.23 & 0.04 & 0.55 & 0.72 \\
\hline & & $u_{h}$ & 0.90 & 0.91 & 0.72 & 0.79 & 0.65 & 0.04 & 0.58 & 0.76 \\
\hline \multirow[t]{2}{*}{$0.5 \times \mathrm{Ji}-\mathrm{ji}$} & \multirow[t]{2}{*}{0.1847} & $u_{s}$ & 0.79 & 0.81 & 0.26 & 0.95 & 0.98 & 0.18 & 0.37 & 0.82 \\
\hline & & $u_{h}$ & 0.92 & 0.92 & 0.28 & 0.80 & 1.04 & 0.18 & 0.40 & 1.00 \\
\hline \multirow[t]{2}{*}{$1.0 \times \mathrm{Ji}-\mathrm{ji}$} & \multirow[t]{2}{*}{0.3693} & $u_{s}$ & 0.91 & 0.94 & 0.73 & 0.95 & 0.68 & 0.08 & 0.68 & 0.89 \\
\hline & & $u_{h}$ & 0.93 & 0.96 & 0.81 & 0.95 & 0.73 & 0.08 & 0.69 & 0.76 \\
\hline \multirow[t]{2}{*}{$1.5 \times \mathrm{Ji}-\mathrm{ji}$} & \multirow[t]{2}{*}{0.5540} & $u_{s}$ & 0.97 & 1.00 & 0.80 & 1.00 & 0.91 & 0.05 & 0.68 & 0.88 \\
\hline & & $u_{h}$ & 0.99 & 1.00 & 0.85 & 0.99 & 1.55 & 0.05 & 0.70 & 0.76 \\
\hline \multirow[t]{2}{*}{$2.0 \times \mathrm{Ji}-\mathrm{ji}$} & \multirow[t]{2}{*}{0.7386} & $u_{s}$ & 0.95 & 1.00 & 0.81 & 0.98 & 1.01 & 0.04 & 0.72 & 0.93 \\
\hline & & $u_{h}$ & 1.00 & 1.01 & 0.85 & 0.94 & 1.11 & 0.04 & 0.74 & 0.80 \\
\hline \multirow[t]{2}{*}{$0.5 \times$ Erzinkan } & \multirow[t]{2}{*}{0.2478} & $u_{s}$ & 0.80 & 0.91 & 0.65 & 1.61 & 1.17 & 0.15 & 0.72 & 1.26 \\
\hline & & $u_{h}$ & 0.96 & 1.02 & 0.80 & 1.46 & 0.87 & 0.15 & 0.65 & 1.21 \\
\hline \multirow[t]{2}{*}{ 1.0× Erzinkan } & 0.4956 & $u_{s}$ & 1.08 & 1.09 & 0.47 & 0.84 & 1.08 & 0.07 & 0.44 & 1.06 \\
\hline & & $u_{h}$ & 1.11 & 1.15 & 0.53 & 0.87 & 1.13 & 0.07 & 0.50 & 0.99 \\
\hline 1.5× Erzinkan & 0.7434 & $u_{s}$ & 1.07 & 1.07 & 0.64 & 0.77 & 1.06 & 0.05 & 0.58 & 0.99 \\
\hline & & $u_{h}$ & 1.09 & 1.09 & 0.65 & 0.79 & 0.97 & 0.05 & 0.59 & 0.87 \\
\hline 2.0× Erzinkan & 0.9912 & $u_{s}$ & 1.07 & 1.09 & 0.74 & 0.88 & 1.05 & 0.04 & 0.62 & 1.01 \\
\hline & & $u_{h}$ & 1.07 & 1.09 & 0.74 & 0.85 & 1.04 & 0.04 & 0.62 & 0.82 \\
\hline
\end{tabular}

Note. $\mathrm{FP}=$ fault parallel; $\mathrm{PGA}=$ peak ground acceleration 
that has been previously and satisfactorily applied to a benchmark base-isolated building both as an active control ${ }^{3,27}$ or as a semiactive control strategy. ${ }^{28}$ The results are also summarized in Tables 5, 6. For a fair comparison, the value of the design parameter $\rho_{s}$ in Equation 19 is selected as

$$
\rho_{s}=\rho_{h} b,
$$

where the values of both $\rho_{h}$ and $b$ can be found in Table 4. This way, both the control $u_{h}$ in Equation 12 and the control $u_{s}$ in Equation 19 are able to provide the same maximum force. After a detailed observation of Tables 5, 6, the following remarks can be concluded, in terms of the evaluation criteria related to several structural aspects:

- the controller $u_{s}$ in Equation 19 is able to reduce the peak base and structure shear $\left(J_{1}\right.$ and $\left.J_{2}\right)$ with more intensity than the proposed approach in this work;

- both controllers perform similarly in reducing the peak base displacement $\left(J_{3}\right)$, though they are almost always slightly better (smaller) for $u_{s}$

- the proposed approach in this work, in Equations 12-13, is able to reduce or maintain the peak interstory $\operatorname{drift}\left(J_{4}\right)$ with respect to the controller $u_{s}$ in 14 out of 32 cases;

- both controllers perform similarly in reducing the peak absolute floor acceleration $\left(J_{5}\right)$;

- the proposed approach in this work, in Equations 12-13, requires the same control effort $\left(J_{6}\right)$ than the controller $u_{s}$; and

- the proposed approach in this work is able to significantly reduce the RMS base displacement $\left(J_{7}\right)$ as the controller $u_{S}$; besides, the RMS absolute floor acceleration $\left(J_{8}\right)$ is reduced with more intensity in 27 out of 32 cases when compared with the controller $u_{s}$.

\section{4 | CONCLUDING REMARKS}

An active control law with interesting features has been proposed in this work. The key idea is to actively reproduce the goodness of hysteretic passive base isolators. Although the designed control strategy is rather simple, it not only adequately reduces, in most cases, the peak base displacement and the peak absolute floor acceleration but also dramatically diminishes their equivalent RMS measures in almost all of the studied earthquakes. On the other hand, assuming the maximum force and the maximum rate of change of the real actuator to be used are known, they can be used to design a control signal that inherently satisfies the actuator constraints (using Proposition 1 to select the control parameters). Finally, a comparison study, covering fully active and pure friction damper, is performed. The response to several earthquake excitations is computed. Numerical simulations suggest that the proposed active control shows significant promise in base-isolation applications, even taking into account the inherent rate limit of the control strategy. As a future work, we would like to improve the control law by introducing acceleration feedback information.

\section{ACKNOWLEDGEMENTS}

This work has been partially funded by the Spanish Ministry of Economy and Competitiveness through the research projects DPI2017-82930-C2-1-R, DPI2014-58427-C2-1-R, and DPI2015-64170-R (MINECO/FEDER) and by the Catalonia Government (Generalitat de Catalunya) through the research project 2017 SGR 388.

\section{ORCID}

Francesc Pozo (iD) http://orcid.org/0000-0001-8958-6789

Yolanda Vidal (iD) http://orcid.org/0000-0003-4964-6948

Leonardo Acho (iD) http://orcid.org/0000-0002-4965-1133

José Rodellar (i) http://orcid.org/0000-0002-1514-7713

\section{REFERENCES}

1. Kelly JM, Marsico MR. The influence of damping on floor spectra in seismic isolated nuclear structures. Struct Control Health Monit. 2015;22(4):743-756.

2. Van Engelen NC, Kelly JM. Retest of neoprene seismic isolation bearings after 30 years. Struct Control Health Monit. 2015;22(1):139-151.

3. Pozo F, Montserrat PM, Rodellar J, Acho L. Robust active control of hysteretic base-isolated structures: Application to the benchmark smart base-isolated building. Struct Control Health Monit. 2008;15(5):720-736. 
4. Saaed TE, Nikolakopoulos G, Jonasson JE, Hedlund H. A state-of-the-art review of structural control systems. J Vib Control. 2015;21(5):919-937.

5. Casciati F, Rodellar J, Yildirim U. Active and semi-active control of structures-theory and applications: A review of recent advances. J Intell Mater Syst Struct. 2012;23(11):1181-1195.

6. Basu B, Bursi OS, Casciati F, et al. A European association for the control of structures joint perspective. Recent studies in civil structural control across Europe. Struct Control Health Monit. 2014;21(12):1414-1436.

7. Chen B, Sun YZ, Li YL, Zhao SL. Control of seismic response of a building frame by using hybrid system with magnetorheological dampers and isolators. Adv Struct Eng. 2014;17(8):1199-1215.

8. Behrooz M, Wang X, Gordaninejad F. Modeling of a new semi-active/passive magnetorheological elastomer isolator. Smart Mater Struct. 2014;23(4):045 013.

9. Oliveira F, Botto MA, Morais P, Suleman A. Semi-active structural vibration control of base-isolated buildings using magnetorheological dampers. J Low. Freq Noise Vib Act Control. 2017. https://doi.org/10.1177/146134841772595

10. Li Y, Li J, Li W, Samali B. Development and characterization of a magnetorheological elastomer based adaptive seismic isolator. Smart Mater Struct. 2013;22(3):035 005.

11. Vu DC, Politopoulos I, Diop S. A new semi-active control based on nonlinear inhomogeneous optimal control for mixed base isolation. Struct Control Health Monit. 2017;25(1):e2032.

12. Gu X, Yu Y, Li J, Li Y. Semi-active control of magnetorheological elastomer base isolation system utilising learning-based inverse model. J Sound Vib. 2017;406:346-362.

13. Djedoui N, Ounis A, Pinelli J, Abdeddaim M. Hybrid control systems for rigid buildings structures under strong earthquakes. Asian J Civ Eng (BHRC). 2017;18(6):893-909.

14. Yamamoto M, Sone T. Behavior of active mass damper (AMD) installed in high-rise building during 2011 earthquake off Pacific coast of Tohoku and verification of regenerating system of AMD based on monitoring. Struct Control Health Monit. 2014;21(4):634-647. https://doi.org/10.1002/stc. 1590

15. Hu T, Lin Z. Control Systems with Actuator Saturation: Analysis and Design. Boston: Springer Science \& Business Media; 2001.

16. Shiroei M, Toulabi MR, Ranjbar AM. Robust multivariable predictive based load frequency control considering generation rate constraint. Int J Electr Power Energy Syst. 2013;46:405-413.

17. Yuan R, Tan X, Fan G, Yi J. Robust adaptive neural network control for a class of uncertain nonlinear systems with actuator amplitude and rate saturations. Neurocomputing. 2014;125:72-80.

18. Lim YH, Ahn HS. Decentralized control of nonlinear interconnected systems under both amplitude and rate saturations. Automatica. 2013;49(8):2551-2555.

19. Mazza F. Displacement-based seismic design of hysteretic damped braces for retrofitting in-plan irregular rc framed structures. Soil Dyn Earthq Eng. 2014;66:231-240.

20. Cancellara D, De Angelis F. A base isolation systemfor structures subject to extreme seismic events characterized by anomalous values of intensity and frequency content. Compos Struct. 2016;157:285-302.

21. Ma C, Zhang Y, Tan P, Kennedy D, Williams F, Zhou F. Non-stationary seismic response analysis of base-isolated buildings with many hysteretic devices. Comput Struct. 2013;123:39-47.

22. Roy BK, Chakraborty S, Mihsra SK. Robust optimum design of base isolation system in seismic vibration control of structures under uncertain bounded system parameters. J Vib Control. 2014;20(5):786-800.

23. Ramallo J, Johnson E, Spencer Jr B. Smart base isolation systems. J Eng Mech. 2002;128(10):1088-1099.

24. Alqado TE, Nikolakopoulos G. Posicast control of structures using MR dampers. Struct Control Health Monit. 2016;23(8):1121.

25. Alqado TE, Nikolakopoulos G, Dritsas L. Semi-active control of flexible structures using closed-loop input shaping techniques. Struct Control Health Monit. 2016;24(5):e1913.

26. Ikhouane F, Rodellar J. Systems with Hysteresis: Analysis, Identification and Control Using the Bouc-Wen Model. Hoboken, NJ: John Wiley \& Sons; 2007.

27. Pujol G, Acho L, Pozo F, Rodríguez A, Vidal Y. A velocity based active vibration control of hysteretic systems. Mech Syst Signal Process. 2011;25(1):465-474

28. Bahar A, Pozo F, Acho L, Rodellar J, Barbat A. Hierarchical semi-active control of base-isolated structures using a new inverse model of magnetorheological dampers. Comput Struct. 2010;88(7):483-496.

29. Pozo F, Acho L, Rodellar J. Hyperbolic control for vibration mitigation of a base-isolated benchmark structure. Struct Control Health Monit. 2009;16(7-8):766-783.

30. Pujol G, Acho L, Pozo F, Rodellar J. A nonlinear damping control for the vibration mitigation of the benchmark highway bridge. Struct Control Health Monit. 2009;16(5):586-598.

31. Tan P, Agrawal AK. Benchmark structural control problem for a seismically excited highway bridge - Part II: phase I sample control designs. Struct Control Health Monit. 2009;16(5):530-548.

32. Agrawal A, Tan P, Nagarajaiah S, Zhang J. Benchmark structural control problem for a seismically excited highway bridge - Part I: Phase I problem definition. Struct Control Health Monit. 2009;16(5):509-529.

33. Nagarajaiah S, Narasimhan S, Agrawal A, Tan P. Benchmark structural control problem for a seismically excited highway bridge - Part III: Phase II Sample controller for the fully base-isolated case. Struct Control Health Monit. 2009;16(5):549-563.

34. Tutivén C, Vidal Y, Acho L, Rodellar J. Hysteresis-based design of dynamic reference trajectories to avoid saturation in controlled wind turbines. Asian J Control. 2017;19(2):438-449. 
35. Pozo F, Ikhouane F, Pujol G, Rodellar J. Adaptive backstepping control of hysteretic base-isolated structures. J Vib Control. 2006;12(4):373-394.

36. Ghaderi P, Amini F. Adaptive block backstepping control for civil structures with unknown parameters subjected to seismic excitation. Struct Control Health Monit. 2017;24(2):e1875. https://doi.org/10.1002/stc.1875

37. Ikhouane F, Mañosa V, Rodellar J. Adaptive control of a hysteretic structural system. Automatica. 2005;41(2):225-231.

38. Skinner RI, Robinson WH, McVerry GH. An Introduction to Seismic Isolation. New York: John Wiley \& Sons; 1993.

39. Luo N, Rodellar J, Vehı J, De la Sen M. Composite semiactive control of a class of seismically excited structures. J Franklin Inst. 2001;338(2):225-240.

40. Kelly J, Leitmann G, Soldatos A. Robust control of base-isolated structures under earthquake excitation. J Optim Theory Appl. 1987;53(2):159-180.

41. Mondal PD, Ghosh AD, Chakraborty S. Control of underground blast induced building vibration by shape-memory-alloy rubber bearing (SMARB). Struct Control Health Monit. 2017;24(10):e1983.

42. Zhang R, Phillips BM. Performance and protection of base-isolated structures under blast loading. J Eng Mech. 2015;142(1):04015 063.

43. Narasimhan S, Nagarajaiah S, Johnson EA, Gavin HP. Smart base-isolated benchmark building. part I: problem definition. Struct Control Health Monit. 2006;13(2-3):573-588.

How to cite this article: Pozo F, Vidal Y, Garcia G, Acho L, Rodellar J. Hysteretic active control of base-isolated buildings. Struct Control Health Monit. 2018;e2206. https://doi.org/10.1002/stc.2206

\section{APPENDIX A: EVALUATION CRITERIA}

The following eight evaluation criteria or performance indices are defined to assess the performance of the proposed active control. These indices are based on both maximum and RMS responses of the building. In this sense, the term uncontrolled refers to the base-isolated structure with no active control. These performance indices are reproduced here to assist the reader in comprehending this work, where $i$ is the floor number, $1, \ldots, 5$; $q$ the earthquake number, $1, \ldots, 16$; and $t$ the time, $0 \leq t \leq T_{q}$. These eight evaluation criteria are in line with the information typically used to design and analyze typical civil structures. ${ }^{43}$

1. Peak base shear (isolation level) in the controlled structure normalized by the corresponding shear in the uncontrolled structure:

$$
J_{1}(q)=\frac{\max _{t}\left|V_{\mathrm{b}}(t, q)\right|}{\max _{t}\left|\hat{V}_{\mathrm{b}}(t, q)\right|}=\frac{\max _{t}\left|m_{\mathrm{b}} \ddot{x}_{\mathrm{b}}+\sum_{i=1}^{5} m_{i} \ddot{x}_{i}(t, q)\right|}{\max _{t}\left|m_{\mathrm{b}} \ddot{\hat{x}}_{\mathrm{b}}+\sum_{i=1}^{5} m_{i} \ddot{\hat{x}}_{i}(t, q)\right|} .
$$

2. Peak structure shear (at the first-story level) in the controlled structure normalized by the corresponding shear in the uncontrolled structure:

$$
J_{2}(q)=\frac{\max _{t}\left|V_{1}(t, q)\right|}{\max _{t}\left|\hat{V}_{1}(t, q)\right|}=\frac{\max _{t}\left|\sum_{i=1}^{5} m_{i} \ddot{x}_{i}(t, q)\right|}{\max _{t}\left|\sum_{i=1}^{5} m_{i} \ddot{\hat{x}}_{i}(t, q)\right|} .
$$

3. Peak base displacement or isolator deformation in the controlled structure normalized by the corresponding displacement in the uncontrolled structure:

$$
J_{3}(q)=\frac{\max _{t}\left|x_{\mathrm{b}}(t, q)\right|}{\max _{t}\left|\hat{x}_{\mathrm{b}}(t, q)\right|} .
$$

4. Peak interstory drift in the controlled structure normalized by the corresponding interstory in the uncontrolled structure:

$$
J_{4}(q)=\frac{\max _{t, i}\left|x_{i+1}(t, q)-x_{i}(t, q)\right|}{\max _{t, i}\left|\hat{x}_{i+1}(t, q)-\hat{x}_{i}(t, q)\right|} .
$$


5. Peak absolute floor acceleration in the controlled structure normalized by the corresponding acceleration in the uncontrolled structure:

$$
J_{5}(q)=\frac{\max _{t, i}\left|\ddot{x}_{i}(t, q)\right|}{\max _{t, i}\left|\ddot{\hat{x}}_{i}(t, q)\right|} .
$$

6. Peak force generated by all control devices normalized by the peak base shear in the controlled structure:

$$
J_{6}(q)=\frac{\max _{t}|u(t, q)|}{\max _{t}\left|V_{\mathrm{b}}(t, q)\right|} .
$$

7. RMS base displacement in the controlled structure normalized by the corresponding RMS base displacement in the uncontrolled structure:

$$
J_{7}(q)=\frac{\sigma_{d}(t, q)}{\hat{\sigma}_{d}(t, q)}=\frac{\sqrt{\frac{1}{T_{q}} \int_{0}^{T_{q}} x_{\mathrm{b}}(t, q) d t}}{\sqrt{\frac{1}{T_{q}} \int_{0}^{T_{q}} \hat{x}_{\mathrm{b}}(t, q) d t}} .
$$

8. RMS absolute floor acceleration in the controlled structure normalized by the corresponding RMS acceleration in the uncontrolled structure:

$$
J_{8}(q)=\frac{\max _{i} \sigma_{a}(t, q)}{\max _{i} \hat{\sigma}_{a}(t, q)}=\frac{\max _{i} \sqrt{\frac{1}{T_{q}} \int_{0}^{T_{q}} \ddot{x}_{i}(t, q) d t}}{\max _{i} \sqrt{\frac{1}{T_{q}} \int_{0}^{T_{q}} \ddot{\hat{x}}_{i}(t, q) d t}}
$$

